\title{
Editorial
}

\section{Optics to the World}

\section{Costantino De Angelis}

Editor in Chief of Optics, Department of Information Engineering, University of Brescia, Piazza del Mercato, 15, 25121 Brescia BS, Italy; costantino.deangelis@unibs.it

Received: 22 June 2020; Accepted: 22 June 2020; Published: 25 June 2020

Optics play a vital role in today's society. The field of opportunity is vast and ranges, for example, from telecommunications to healthcare and energy. Future success in many optical disciplines depends on continuous innovation and technological development, which requires a constant influx of research results. This new open access journal will adopt a holistic approach to cover the theoretical, computational, physical, and engineering aspects of modern optics. We aim to provide easy access to high-quality research for as many scientists as possible, disseminate the latest research results, promote communication between researchers, and connect theory with practice. We encourage scientists to publish their experimental and theoretical results in as much detail as possible, and there are no restrictions on the length of the work.

On behalf of the editorial board members, we are honored to present Optics, an academic open access journal with peer review, and to invite you to contribute your articles or submit proposals for special issues. We rely heavily on your advice and suggestions and are confident that this magazine will contribute greatly to promoting the advancement of the optical sciences.

(C) 2020 by the author. Licensee MDPI, Basel, Switzerland. This article is an open access article distributed under the terms and conditions of the Creative Commons Attribution (CC BY) license (http://creativecommons.org/licenses/by/4.0/). 